\title{
FOUCAULT E A PARRESÍA: APONTAMENTOS PARA A CONSTRUÇÃO DE UMA EXPERIÊNCIA ÉTICA EM EDUCAÇÃO
}

FOUCAULT AND THE PARRHESIA: INDICATIONS FOR THE CONSTRUCTION OF AN ETHICAL
EXPERIENCE IN EDUCATION

Rodrigo Diaz de Vivar y Soler ${ }^{*}$

Leonardo Ferreira Krolikowski** $^{* *}$

\section{RESUMO}

Michel Foucault dedicou seus últimos trabalhos ao estudo da parresía no contexto do mundo antigo. Estabelecendo uma genealogia que percorre desde os textos clássicos dos filósofos gregos até as primeiras epístolas dos cristãos primitivos, ele procura ilustrar como, no mundo antigo, a atitude parresiástica compunha um dos principais estilos do sujeito em relação à verdade por meio da coragem da verdade. Nesse sentido, é correto afirmar que a parresía consiste numa ruptura para pensarmos a construção de uma experiência ética que ultrapasse todos os acossamentos dos dispositivos normalizadores. O presente artigo possui como finalidade explorar a relação da parresía com a construção de uma experiência ética em educação. Assumindo o preceito foucaultiano de que a atividade intelectual na contemporaneidade passa pela problematização das verdades como desdobramento e problematização das políticas de identidade, o que afirmamos é a necessidade imediata de pensarmos com Foucault na parresía como uma linha de fuga contra os processos de assujeitamento presentes na nossa sociedade. Produzir este estilo de pensamento implica, portanto, na concessão de uma nova leitura sobre a educação situada não mais como disciplinalização normativa dos corpos, mas como experiência ética nos modos como o sujeito se constitui pela coragem da verdade.

PALAVRAS-CHAVE: Michel Foucault. Parresía. Experiência Ética. Educação.

\section{ABSTRACT}

Michel Foucault devoted his last work study's of parresia in the context of the ancient world . Establishing a genealogy that runs from classical texts of Greek philosophers until the early epistles of the early Christians, Foucault seeks to illustrate how the ancient world, the attitude

\footnotetext{
* Bacharel em Psicologia pela UNESC. Mestre em Psicologia pela UFSC. Doutorando em Filosofia pela UNISINOS. Professor do Centro Universitário Estácio Santa Catarina. E-mail: diazsoler@gmail.com

${ }^{* *}$ Graduando em Psicologia pela UNISINOS. E-mail: 1fkrolikowski@gmail.com
} 
parresiastic's composed one of the main styles of the subject stating the truth about himself through the courage of the truth. In this sense, it is correct to say that parresia is a possible loophole to think about building an ethical experience that exceeds all acossamentos devices such as biopolitics, for example. The proposed work has as purpose to explore the relationship of parrhesia as a condition of possibility for the construction of an ethical experience in education. Taking Foucauldian precept that the contemporary intellectual activity involves the questioning of truths as a development and questioning of identity politics which is now affirm the immediate need to think with Foucault in the execution of parresia as an immediate possibility, as a line of flight from the processes of subjection in our society . Produce this style of thinking, therefore, imply the granting of a new reading on education situated not as a disciplinary device, but how ethical experience in the ways the guy talks about himself from the power of the truth.

KEYWORDS: Michel Foucault. Parresia. Ethical Experience. Education.

\section{INTRODUÇÃO}

Apresentamos neste ensaio nossas considerações acerca do papel da parresía em Michel Foucault e seus desdobramentos para uma experiência ética na educação. Foucault dedicou nos seus últimos anos de vida uma intensa preocupação com o resgate desse conceito, por meio de um amplo diálogo com a filosofia antiga para poder buscar os elementos intrínsecos à coragem da verdade. Detendo-se com acuidade sobre textos considerados emblemáticos para o pensamento ocidental, Foucault operou uma genealogia das práticas de veredicção empreendidas pelo sujeito para sublinhar os traços da relação de uma experiência ética desdobrada na coragem, pois só podia empreender a parresía aquele que se colocava, por vontade própria, diante de uma situação de risco iminente.

Mas, quais seriam, exatamente as consequências dessa atitude-limite da parresía para o contexto da educação? O que teria Foucault a dizer para aqueles que procuram pensar as condições de possibilidade desse conceito nos dias de hoje? Longe de procurarmos estabelecer respostas conclusivas a tais questões, se faz necessário investigar no interior de enunciação dessas duas perguntas uma possível retomada do sentido da palavra parresía para a educação nos dias de hoje, apoiando-nos na porosidade textual do pensamento foucaultiano para a ilustração de uma ontologia histórica de nós mesmos, concebendo, de tal modo, a educação um estatuto limitado não mais ao campo epistemológico, mas também ao político. 
Nesse sentido, a experiência ética em educação se efetiva como um processo de confronto, por parte do sujeito em relação ao acossamento dos dispositivos, pois conforme argumenta Freitas (2013, p. 329-330):

\begin{abstract}
Por essa via, a cisão entre filosofia e espiritualidade, enunciada por Foucault, mostra que a formação de si exige pôr em jogo processos que permitam a um sujeito qualquer adquirir, de um lado, discursos verdadeiros de que se tem necessidade em determinadas circunstâncias da vida e, por outro, fazer de si mesmo um sujeito ativo desses discursos. Essa é a razão pela qual ele insiste em um conjunto articulado de distinções que se desdobram polarizadas ao longo dos seus cursos tardios: cuidado de si e conhecimento de si; saber de espiritualidade e saber de conhecimento; conhecimentos inúteis e conhecimentos úteis; filosofia e retórica; filosofia e pedagogia. Foucault aciona esse conjunto de clivagens conceituais e metodológicas que emergem da diferenciação primeira entre filosofia e espiritualidade, e que visam articular a separação entre o conhecimento apreendido como ornamento da cultura e o conhecimento que modifica a natureza mesma do sujeito, ou melhor, a sua maneira de agir, o seu êthos.
\end{abstract}

Desenvolver uma leitura acerca da parresía em Michel Foucault consiste em estabelecer uma problematização sobre as condições de possibilidade para o exercício da atividade intelectual enquanto uma dimensão ontológica inscrita numa prática política voltada para o engajamento através de uma postura crítica e combativa por meio da transversalidade das lutas e, nesse sentido, não há como recorrer à evocação da parresía sem situar a educação como um dos possíveis campos de análise por meio do qual o sujeito procura, através do franco falar, elaborar um ethos que se projeta para a transformação do seu próprio fazer uma vez que a prática educacional situa-se como um instrumento, uma bandeira de combate a toda e qualquer forma de alienação. Dir-se-ia provocativamente que a articulação possível na parresía corresponde à elaboração de estratégias de combate às formas miúdas de fascismo que insistem em se manifestar na nossa existência da qual a função de educador é debitaria direta.

Em O Sujeito e o poder, Michel Foucault (1995) nos ensina a pensar um posicionamento estratégico voltado para uma prática política direcionada contra as formas de assujeitamento exercidas não mais pelos contornos dos aparelhos ideológicos de Estado, mas sim na capilaridade da destruição dos jogos de identidade como um dos grandes desafios a serem enfrentados na nossa contemporaneidade. Isso significa que tal posicionamento acarreta um duplo efeito para uma leitura sobre as correlações entre a parresía e a educação referendada pela veia das relações de força da desconstrução nietzschiana. A emergência dessa correlação implica, por sua vez, construção de um modo de ser educador comprometido em estabelecer uma problematização dos modos de assujeitamento presentes nas práticas 
sociais perante a coragem de enunciar uma determinada verdade, mesmo que isso implique o risco de esse intelectual pagar com a vida pelo seu ato provocativo.

Existe ainda uma implicação ética para o exercício da parresía no contexto da educação que passa pela adoção da possibilidade de se viver em acordo com aquilo pelo que acredita ser o mais correto uma produção de uma estética da existência que procura delimitar uma consonância através do exercício de uma experiência limite com aquilo que se vive, com aquilo que se diz. Tal perspectiva implica por sua vez a imediata possibilidade de estabelecermos uma relação com o contexto da parresía na educação como uma deliberação de uma atitude existencial a qual é possível de se reconhecer na própria trajetória de militância de Foucault, uma vez que ele sempre procurou delimitar na sua produção acadêmica um processo de captura sobre temas delicados, ou melhor, caros à sociedade ocidental. A loucura, a monstruosidade, a homossexualidade foram muito mais do que objetos de análise, foram na realidade a maneira encontrada por Foucault de situar seu pensamento a favor da infâmia do mundo.

Nesse contexto, a experiência ética da educação a partir da parresía configura-se como um gesto político e histórico que visa permitir ao sujeito proceder uma ascese pela perspectiva da mediação entre bios $X$ verdade $X$ logos e que encontram na emblemática figura de Sócrates seu apogeu dentro do exercício da virtude como modo de vida referendado pela perspectiva do escândalo da verdade. Para Cardoso Júnior (2005), ao recorrer aos gregos e aos romanos para traçar uma genealogia das práticas de si, Foucault acaba criando uma análise histórica e ontológica dos processos de subjetivação compreendidos como um processo que no mundo antigo se exercia por duas perspectivas. No primeiro momento, uma relação intensa envolta em uma atividade pela qual as práticas de si evidenciavam a conduta do sujeito com relação à coragem da verdade; e num segundo momento, pela analítica dos modos pelos quais o sujeito constituía a si mesmo como senhor do seu próprio destino. São essas duas dobras que permitem-nos pensar o contexto educacional como elemento possível da emancipação ética e da autonomia nos dias de hoje.

\section{Foucault e a parresía: desdobramentos para a construção de uma experiência ética em educação}

Diferentemente de outros muitos, Foucault não foi um filósofo de gabinete. Não lhe interessava interpretar o mundo a partir de determinada estrutura argumentativa ou baseado 
em certos critérios provenientes de certo ceticismo epistemológico. Ele também não foi um historiador tradicional interessado em apenas fazer convergir aos seus objetos de análise os elementos de gêneses lineares que circulariam em torno das noções de progresso ou de racionalidade. Inclassificável por excelência, o pensamento desenvolvido por Foucault estaria próximo do que Deleuze (1988) chama de manhã de festa, isto é, a anunciação de uma orgia dionisíaca que dilacera os saberes, denuncia a precariedade das relações de poder e faz delirar outras formas de subjetividade. Nesse sentido, é necessário apresentar a perspectiva do pensamento foucaultiano como uma proliferação de rupturas políticas, ontológicas e epistemológicas. Nesse contexto, o que está em jogo são os constantes movimentos de deslocamentos produzidos na exterioridade dos acontecimentos. Desse modo, o que Foucault pretende nos mostrar é que, se por um lado a história do pensamento ocidental configura-se como um amontoado de engrenagens cristalizadas, é necessário produzir um inventário sobre os acontecimentos através da análise dos seus efeitos de irrupção de forças no tempo presente por meio da incessante investida contra os enunciados, não no sentido de procurar decifrá-los, mas trabalhar de modo a esgotá-los. Em outras palavras trata-se, para Foucault, de perceber a própria potência dos discursos, dos poderes e dos processos de subjetivação.

Nesse sentido, o pensamento foucaultiano torna-se compreensivo à medida que abandonamos a pretensão de buscar associá-lo a qualquer matriz epistemológica em nome do que chamamos de história política dos sistemas de pensamento.

Podemos recolher indicativos dessa história política dos sistemas de pensamento ao recorrermos aos últimos trabalhos de Foucault, mais precisamente os livros $O$ uso dos prazeres e $O$ cuidado de si (FOUCAULT, 1984, 1985), bem como os cursos no Collège de France $A$ hermenêutica do sujeito, $O$ governo de si e dos outros e $A$ coragem da verdade (FOUCAULT, 2010a, 2010b, 2011). Percorrendo a porosidade textual desses escritos podemos encontrar um projeto comum: apresentar um panorama da cultura antiga associada à genealogia da ética dos processos de subjetivação. Um projeto ambicioso que se desdobra pela filosofia grega, passa pela filosofia romana e sobre o cristianismo primitivo através do estudo sobre modos de vida e guias de conduta que fazem emergir nesse contexto uma leitura em torno dos modos de subjetivação. Subjetivação esta que, segundo Deleuze (2005) consiste na produção de estranhamento, ou seja, o momento pelo qual algumas palavras elaboram infames confrontos contra o poder. Nesse sentido, a subjetivação seria o choque contra a estratificação das políticas de identidade. Na introdução de $O$ uso dos prazeres Foucault reconhece que era preciso analisar esse processo tomando distância dos velhos jogos de 
identidade para fazer emergir um desdobramento analítico da subjetivação compreendida não como interioridade, mas como algo que pertence às dobras do lado de dentro. Algo muito mais poroso do que o mundo interior. Segundo ele

\begin{abstract}
Devia escolher: ou manter o plano estabelecido, fazendo-o acompanhar de um rápido exame histórico desse tema do desejo, ou reorganizar todo o estudo em torno da lenta formação, durante a Antiguidade, de uma hermenêutica de si. E foi por este último partido que optei ao pensar que, afinal de contas, aquilo a que me atenho - a que me ative desde tantos anos - é a tarefa de evidenciar alguns elementos que possam servir para uma história da verdade. Uma história que não seria aquela do que poderia haver de verdadeiro nos conhecimentos; mas uma análise dos "jogos de verdade", dos jogos entre o verdadeiro e o falso, através dos quais o ser se constitui historicamente como experiência, isto é, como podendo e devendo ser pensado. (FOUCAULT. 1984, p. 1984).
\end{abstract}

A projeção imposta por Foucault acaba por permitir pensar a subjetivação como linha de fuga que escapa dos processos de assujeitamento. Mas acima de tudo, tal desafio coloca algumas perguntas: contra o quê é preciso lutar? Que forças são essas enfrentadas pela subjetivação? Encontramos uma possível resposta ao nos debruçarmos sobre o fato de que, para Foucault deflagrar uma guerra contra o poder implica problematizar seu pensamento, sua estrutura e sua operacionalidade. Ou seja, a questão não passa pela compreensão da subjetivação como uma projeção do mundo interior, mas como uma curvatura potencializada pelo desdobramento do fora.

Um desdobramento semelhante, segundo Deleuze (2005), a reduplicação do Outro e não uma reprodução do mesmo. Trata-se de uma metáfora do lance de dados. Os jogos de repetição que convergem para um fora desdobra-se na diferença dos processos de subjetivação através da elaboração do grande dilema ético: governar a si mesmo para governar os outros. Tal empreendimento está implicado no fato de que a relação consigo mesmo era, no mundo antigo, em especial na Grécia o preceito responsável por orientar todas as condutas por meio do cuidado de si. No curso A hermenêutica do sujeito Foucault (2010a, p. 09) ilustra que na cultura grega, por exemplo,

O cuidado de si vai ser considerado, portanto, como o momento do primeiro despertar. Situa-se exatamente no momento em que os olhos se abrem, em que se sai do sono e se alcança a luz primeira: este, o terceiro ponto interessante na questão do "ocupar-se consigo mesmo." E finalmente, o término de uma passagem que também não li: a célebre comparação entre Sócrates e o tavão, esse inseto que persegue os animais, pica-os e os faz correr e agitar-se. O cuidado de si é uma espécie de aguilhão que deve ser implementado na carne dos homens, cravado na sua existência, e constitui um principio de agitação, um principio de movimento, um princípio de permanente inquietude no curso da existência.

Sapere aude - Belo Horizonte, v. 7 - n. 12, p. 256-268, Jan./Jun. 2016 - ISSN: 2177-6342 
Desse modo, percebe-se como no contexto do mundo antigo a preocupação do sujeito, ou a inquietude de si constituía-se como o elemento preponderante da atitude ética, cujo emblema maior seria representado pela figura de Sócrates que, na opinião de Foucault teria sido o responsável por aceitar para si a tarefa de incitar a juventude ateniense ao cuidado de si mesmo e dos outros. Reconhecemos a atitude ao revisitarmos o texto de Platão (2004) Apologia de Sócrates em que o mestre do cuidado de si não só recusa aceitar a condenação que lhe é imposta pelos juízes, como defende que deveria ser homenageado pelo seu estilo de vida, a ponto de afirmar que, por conta de suas convicções, jamais adotaria outro modo de vida, pois Sócrates acreditava que suas ações sempre deveriam estar em consonância com suas palavras.

Foucault aponta no diálogo platônico três momentos em que emerge a força de Sócrates contra seus acusadores. No primeiro momento, ele trata de deixar claro que a atitude de exortar os sujeitos a ocuparem-se consigo mesmos é uma missão conferida a ele pelos próprios deuses e que, por conta disso, não poderia abrir mão de agir criticamente incitando à produção de uma experiência ética não somente a juventude, mas também os idosos, os forasteiros e também os demais cidadãos atenienses. Nessa tarefa encontra-se, portanto, a chave para a compreensão do cuidado de si como uma ocupação e um estado de vigilância para o exercício político de uma vida em consonância com aquilo que se acredita ser uma perfeita relação entre bios $X$ verdade $X$ logos.

No segundo momento da Apologia, Sócrates desafia seus inquisidores, sugerindo que, caso fosse condenado à morte, a sociedade ateniense acabaria perdendo uma peça-chave para o exercício da virtude do cuidado de si. Vejamos como Foucault, citando Platão (2004, p. 08), aborda a questão:

\footnotetext{
Que tratamento, que multa mereço eu por ter acreditado que deveria renunciar a uma vida tranquila, negligenciar o que a maioria dos homens estima, fortuna, interesse privado, postos militares, sucesso na tribuna, magistraturas, coalizões, facções políticas? Por ter me convencido de que com meus escrúpulos eu me perderia se entrasse por esta via? Por não ter querido me comprometer com o que não tem nenhum proveito nem para vós, nem para mim? Por ter preferido oferecer, a cada um de vós em particular, aquilo que declaro ser o maior dos serviços, buscando persuadi-lo a preocupar-se (epimeletheíe) menos com o que lhe pertence do que com sua própria pessoa, a fim de tornar tão excelente, tão sensato quanto possível, de pensar menos nas coisas da cidade do que na própria cidade, em suma, de aplicar a tudo esses mesmos princípios? Que mereci eu, pergunto, por me ter assim conduzido e por vos ter incitado a vos ocupar com vós mesmos? Nenhuma punição, certamente, nenhum castigo, mas um bom tratamento, atenienses, se quisermos ser justos.
} 
É possível recolher nessas palavras, uma proposta de ensinamento quanto aos interesses do filósofo em preocupar-se com questões realmente importantes deixando de lado todas as outras preocupações materiais como também o status social e político perseguido pelos cidadãos atenienses. A ocupação consigo mesmo desdobra-se aqui em uma atitude que deve ser lida a partir da recusa e do enfrentamento empreendido por Sócrates em relação a todo comodismo oferecido pelas vantagens sociais de uma vida desprovida de qualquer orientação ética.

Já o terceiro momento pode ser descrito como um desdobramento do segundo, pois implicada numa atitude de recusa produzida pela ocupação consigo mesmo. Tratava-se, para Sócrates de uma inquietação permanente que deveria fazer parte da vida do sujeito desde o despertar do dia até o momento crepuscular.

O cuidado de si era compreendido como uma espécie de aguilhão na realidade, Foucault chega a sugerir que tal pressuposto era, para a cultura antiga, uma permanente inquietude responsável por conduzir toda existência do sujeito. Princípio mais de tensão do que de acomodação. Portanto, ocupar-se consigo mesmo significava produzir uma experiência de conflito, uma proposta que compreendia a vida como uma agonística, princípio segundo o qual as relações sociais existentes eram fortemente mediadas pelo conflito, pela disputa e pela guerra. Lembra-nos Foucault (2004a, p. 09) que "O cuidado de si vai ser considerado, portanto, como o momento do primeiro despertar. Situa-se exatamente no momento em que os olhos se abrem, em que se sai do sono e se alcança a luz primeira (...).”

Nesse sentido, não é nenhum exagero aproximarmos essa atitude crítica do cuidado de si com a parresía, uma vez que, de acordo com Gros (2004), essa tensa aproximação permite visualizar, nos últimos trabalhos de Foucault um (re) atravessamento das questões políticas e éticas responsáveis por correlacionar o problema do governo de si e dos outros ao da ética do cuidado de si através de uma atitude obscurecida ao longo do tempo pela civilização ocidental, mas que no mundo antigo correspondia a uma atitude aristocrática na qual o sujeito por meio da expressão da verdade se colocava em risco iminente.

De difícil tradução para a língua portuguesa, a palavra parresía pode inicialmente ser entendida como franco falar, fala livre ou então, coragem da verdade. De todo modo essas três indicações compõem a performatividade da parresía compreendida por Foucault como uma atividade da fala, por meio da qual o sujeito realiza um ritual discursivo se valendo da sinceridade, da provocação e da ironia. Contudo, a parresía também possui implicações éticas e estéticas. E para que tais implicações sejam compreendidas, se faz necessário empreender o 
seguinte questionamento: quais seriam as diferenças e similitudes entre a parresía e a ocupação de si? Com o intuito de elucidar tal questionamento é necessário que recorramos a outro diálogo de Platão (1985), no caso Laques - ou sobre o valor - em que Sócrates é apresentado não somente como mestre do cuidado de si, mas também como um parresiastes, ou seja, alguém que frequentemente se utiliza da parresía. No início do dialogo Lisímaco e Melesias aparentam estar preocupados com o modelo de educação que desejam oferecer a seus filhos. Ambos pertencem a famílias tradicionais de Atenas, porém, ao longo de suas vidas não exerceram nenhum papel político de destaque.

De imediato é necessário chamar a atenção para o valor dado neste momento do diálogo para a educação compreendida como uma aliança entre a parresía e a ocupação consigo mesmo. Nesse sentido, é preciso que se discuta preliminarmente o modelo de educação a ser empregado no preparo do jovem para suas futuras posições políticas e sociais em Atenas e, mais especificamente, no caso do platonismo, a educação devia ser compreendida como uma atividade desvinculada do modelo sofístico e da retórica, práticas comuns naquela época. A parresía emerge como força necessária à educação como atividade voltada para a franqueza e da preocupação em reconhecer-se no mestre os atributos necessários para distingui-lo dos aproveitadores e dos aduladores.

Essa preocupação é sentida no momento do diálogo em que Lisímaco e Melesias tendo como testemunhas Nícia e Laques, assistem a uma demonstração de Estesilao, figura pública conhecida por deferir golpes com precisão. A crítica empreendida por Laques é que Estesilao é alguém que só realiza suas demonstrações mediante o pagamento em dinheiro sendo, portanto, um sofista das armas e que, portanto, não pode ser considerado um grande guerreiro na opinião de Laques, porque nunca lutou ao lado dos espartanos, considerados melhores soldados do que os atenienses.

$\mathrm{Na}$ realidade, ele não poderia se proclamar nem como mero combatente, uma vez que nunca estivera presente em guerra alguma e, consequentemente, não obtivera nenhuma vitória militar. Mesmo com essas opiniões críticas de Laques, Lisímaco e Melesias entendem que devem procurar por Sócrates. A busca é momento no qual Sócrates aparece como um parresiastes no contexto ético da palavra. Isso porque a parresia exercida por Sócrates não é da ordem da insurreição, nem muito menos de uma provocação pública dirigida a alguém ou a um determinado público, mas uma atitude de proximidade na relação frontal instigada por uma prática linguística que é da ordem da interpelação. Ou seja, Sócrates exerce a função de investigador cujo objetivo final seria o de investigar as consonâncias existentes entre o logos e 
o estilo de vida narrado pelo indivíduo no instante de sua fala. Ao solicitar que Laques fizesse um relato das suas experiências, Sócrates pretendia pôr à prova as atitudes de Laques durante sua vida por meio do seu princípio de inteligibilidade e correlação com o logos.

O exercício realizado por Sócrates permite entender que no contexto do cuidado de si, a figura do parresiastes só pode existir quando acontece uma mediação entre aquilo que se fala e aquilo que se vive. Sócrates seria, segundo Foucault (2004b), um musikós aner, ou seja, uma pessoa fiel tanto às palavras quanto aos atos e, portanto, exercia uma atividade ontológica na qual o logos e o bios se complementam numa estética da existência regrada pela captura da experiência desses princípios.

Nesse sentido, é correto afirmar que a parresía pode ser compreendida como uma força que subleva-se a partir da relação existente entre o sujeito e seu mestre tendo como pano de fundo um caminho que passa pelo aperfeiçoamento da virtude. Trata-se, portanto, de visualizarmos no personagem de Sócrates os traços de uma atitude que toma a coragem da verdade como instrumento de uma manifestação de uma experiência ética por parte do sujeito que toma a figura do educador como intelectual compromissado não somente com a transmissão ou reprodução de um conhecimento, mas sim um estrategista que procura interpelar os sujeitos na correlação entre discurso e ação política.

Nesse caso, falar da parresía como elemento de experiência ética em educação significa compreender a necessidade imediata dos educadores que procuram firmar um compromisso político com a realidade social, pois conforme lembra Paulo Freire (1983, p.16$17)$,

\footnotetext{
Se a possibilidade de reflexão sobre si, sobre seu estar no mundo, associada indissoluvelmente à sua ação sobre o mundo, não existe no ser, seu estar no mundo se reduz a um não poder transpor os limites que lhe são impostos pelo mundo, do que resulta que este ser não é capaz de compromisso. É um ser imerso no mundo, no seu estar, adaptado a ele e sem ter dele consciência. Sua imersão na realidade, da qual não pode sair, nem "distanciar-se" para admirá-la e, assim transformá-la, faz dele um ser fora do tempo ou sob o tempo, ou ainda, num tempo que não é seu. $\mathrm{O}$ tempo para tal ser seria um perpétuo presente. Um eterno hoje. A-histórico, um ser como este não pode comprometer-se; em lugar de relacionar-se com o mundo, o ser imerso nele somente está em contato com ele. Seus contatos não chegam a transformar o mundo, pois deles não resultam produtos significativos capazes de inclusive voltando-se sobre ele marcá-los.
}

Aprofundando esse debate, acreditamos que a experiência ética da educação por meio da parresía consiste, portanto, num processo de luta e de enfrentamento. Ou seja, esse caminhar pelos contornos da virtude e da ética significa perceber a educação como condição 
de possibilidade para emancipação cultural na sociedade brasileira. Uma emancipação que somente emergirá como força de desconstrução no exato momento em que os educadores assumirem para si a tarefa de interpelar os indivíduos problematizando suas práticas e valores produzindo uma práxis educacional voltada para a formação da atividade crítica do pensamento em oposição aos meandros da razão instrumental.

Estas palavras apontam para a constatação de que não existe sociedade possível sem relações de poder. Logo, o problema não é dissolver essas relações através de projetos utópicos como a teoria da comunicação em Habermas - que enfatiza a necessidade da constituição de um consenso coletivo responsável por transparecer e destruir essas relações mas sim indicar os novos contornos de uma existência ética que atenue os efeitos da sujeição.

\section{CONSIDERAÇÕES FINAIS}

Encaminhamos nossas considerações empreendidas no presente ensaio recuperando a imediata necessidade de situarmos a parresía como um conceito empreendido por Foucault a partir de um trabalho do sujeito sobre si mesmo que, no contexto da educação, confere a possibilidade da produção de uma ruptura com os modelos educacionais conservadores, pensando a prática educacional como um instrumento de emancipação cultural interpelando os sujeitos a ocuparam-se consigo mesmos.

Numa de suas últimas conferências, Foucault $(1990$, p.141) tratava de exercer tal função ao proclamar que "No soy um escritor, ni um filósofo, ni tampoco uma gran figura de la vida intelectual [...] No creo que sea necessário saber exactamente lo que soy”. É possível encontramos no interior dessas palavras a emergência Dos processos de subjetivação.

Segundo Revel (2005), ao assinalar a presença da subjetividade como devir, Foucault coloca em evidência a relação porosa entre o trabalho do sujeito sobre si mesmo e as condições históricas das constantes resistências éticas presentes na conduta subjetiva. Essa constatação permite que haja uma superação por parte do sujeito em relação às malhas do saber e do poder a partir de um trabalho de desprendimento que é referendado pela desterritorialização da subjetividade.

Toda essa consideração em torno de uma estética da existência fomentada por Foucault nos habilita a indagar outras formas de produção de subjetividade, inscritas não em correntes epistemológicas, mas sim em uma base política configurada pelas práticas de si e no minucioso estudo dos diversos trabalhos do sujeito sobre si mesmo cujo esplendor é a 
liberdade como modelo de conduta vinculada às formas de enunciação da verdade presentes na parresía, encontrando suas ressonâncias na possibilidade de problematização no que diz respeito à noção de educação no mundo contemporâneo, re-colocando a questão sob um patamar político através da retomada de um ethos em que as práticas de si implicam a fuga e a resistência principalmente no que toca à liberdade aqui entendida como um exercício prático. Em outras palavras, o pensamento foucaultiano, ao retornar a história lendo-a em contrapelo, delibera um confronto por parte do sujeito contra os dispositivos de sujeição e de controle presentes na nossa sociedade.

A consequência brutal desta atitude-limite define-se pelo fato de que a educação assume agora um tom profundamente histórico na medida em que deve percorrer as práticas, os jogos, os discursos e modos de estetização da existência contra as quais é preciso se rebelar. Desse entrecruzamento entre a parresía e a educação, emerge a ontologia histórica de nós mesmos ocupando um papel que está inserido numa atitude experimental da liberdade. Porém, ela não reivindica a liberdade como direito ou garantia, mas estabelece o exercício das rupturas, das transgressões, dos modos de resistência e das práticas de liberdade. Todas elas circulando sobre a perspectiva ética da relação do sujeito consigo mesmo, pois pensar o tempo presente é importante para que se construa uma leitura capaz de capturar os acontecimentos pelo que eles são. Por fim, deve-se ressaltar que não se trata de empreender uma leitura sobre as relações entre parresía e educação cuja finalidade seria a transformação global das coisas, mas sim pensá-las a partir da constituição de um exercício de atenção para com o real de modo que a liberdade possa ser praticada no seu extremo. Nesse sentido, o estatuto correlativo desse processo está intimamente relacionado ao diagnóstico do tempo presente que recai sobre os desdobramentos da práxis educativa no que se refere a sua criticidade.

A tarefa recai, nesse caso, não sobre o conjunto das totalizações, mas sobre a abertura das problematizações. Mais do que encontrar a solução e uma alternativa para as coisas, é preciso questionar as práticas nas suas meticulosidades e nas estratégias de resistência. Não existe uma vontade primeira que nos conduz em direção a determinado objetivo, mas sim a presença de elementos que nos incitam a lutar contra os jogos de poder e contra os limites sob os quais as políticas de identidade são construídas. A tarefa do nosso tempo é questionar a política, colocando um ponto de interrogação sobre o que determinado pensamento tem a dizer em torno dos problemas que o atravessam. Tal afirmação nos auxilia a entender o motivo pelo qual o pensamento está articulado com problemas que são do tempo presente. 


\section{REFERÊNCIAS}

CARDOSO JÚNIOR, Helio. Rebello. Pra quê Serve uma Subjetividade? Foucault, tempo e corpo. Psicologia: reflexão e crítica. v. 03, n.18, p. 343 - 349, 2005.

DELEUZE, Gilles. Foucault. São Paulo: Brasiliense, 2005.

DELEUZE, Gilles. Os Intelectuais e o Poder. In: FOUCAULT, Michel. Microfísica do Poder. Rio de Janeiro: Graal, 1979, p. 69-78.

FOUCAULT, Michel. História da sexualidade II: O uso dos prazeres. Rio de Janeiro: Graal, 1984.

FOUCAULT, Michel. História da sexualidade III: o cuidado de si. Rio de Janeiro: Graal, 1985.

FOUCAULT, Michel. Vigiar e punir. Petrópolis: Vozes, 1987.

FOUCAULT, Michel. Verdad, Individuo y Poder. In FOUCAULT, Michel. Tecnologías del Yo y otros textos afines. Barcelona: Paidos, 1990. p. 141-150.

FOUCAULT, Michel. O Sujeito e o Poder. In: DREYFUS, Hubert. RABINOW, Paul. Michel Foucault: uma trajetória filosófica para além do estruturalismo e da hermenêutica. Rio de Janeiro: Forense Universitária, 1995. p.208-239.

FOUCAULT, Michel. As palavras e as coisas. São Paulo: Martins Fontes, 2008.

FOUCAULT, Michel. A hermenêutica do sujeito. São Paulo: Martins Fontes, 2010a.

FOUCAULT, Michel. O governo de si e dos outros. São Paulo: Martins Fontes, 2010b.

FOUCAULT, Michel. A coragem da verdade. São Paulo: Martins Fontes, 2011c.

FOUCAULT, Michel. A ordem do discurso: aula inaugural no Collège de France pronunciada em 2 de dezembro de 1970. São Paulo: Loyola, 2012.

FREIRE, Paulo. Educação e Mudança. Rio de Janeiro: Paz e Terra, 1983.

FREITAS, Alexandre Simão de. A parresía pedagógica de Foucault e o ethos da educação como psicologia. Rev. Bras. Educ. v. 18, n.53, p. 325-338, 2013. Disponível em: http://www.scielo.br/pdf/rbedu/v18n53/05.pdf

GROS, Frederic. A parresía em Foucault. In: GROS, Frederic (Org.). Foucault: a coragem da verdade. São Paulo: Parábola editorial, 2004.

PLATÃO. Apologia de Sócrates. São Paulo: Abril Cultural, 2004.

PLATÃO. Laques: do valor. São Paulo: Abril Cultural, 1985.

REVEL, Judith. Foucault: conceitos essenciais. São Paulo: Claraluz, 2005.

Sapere aude - Belo Horizonte, v. 7 - n. 12, p. 256-268, Jan./Jun. 2016 - ISSN: 2177-6342 